This article is (c) Emerald Group Publishing and permission has been granted for this version to appear here (https://dspace.lib.cranfield.ac.uk/index.jsp). Emerald does not grant permission for this article to be further copied/distributed or hosted elsewhere without the express permission from Emerald Group Publishing Limited.

\title{
Examining the Academic/Commercial \\ Divide in Marketing Research
}

\author{
Paul R. Baines \\ Cranfield University \\ Ross Brennan \\ Middlesex University \\ Mark Gill \\ Woodnewton Associates \\ Roger Mortimore \\ Ipsos MORI
}

Address for Correspondence:

Dr. Paul Baines

Cranfield School of Management

Cranfield, Bedfordshire

MK43 0AL, UK

Tel.: +44 (0)1234-758041

email: paul.baines@cranfield.ac.uk

\section{Acknowledgement}

The authors gratefully acknowledge the funding received from the Academy of Marketing to support this project.

Accepted for publication, European Journal of Marketing 


\section{Structured Abstract}

\section{Purpose}

To comment on the differences in perceptions that exist between academic and professional marketing researchers, as creators of new marketing knowledge, and explore how academics and practitioners can work together better on areas of mutual interest or separately on areas where there interests do not coincide.

\section{Methodology/approach}

Two focus groups, one with researchers in marketing from universities and one with commercial market researchers. Online surveys of the same target groups, with 638 respondents in all.

\section{Findings}

The study indicates that our two sample groups have relatively congruent views about the advantages and disadvantages of each others' approach to research but both groups believe they could do more to make their research more comprehensible and accessible to each other.

\section{Research limitations/implications}

The empirical study was conducted in the UK only, and the response rate from the university marketing research community was disappointingly low. These represent limitations on the generalisability of the findings.

\section{Practical implications}

We argue that marketing research can be undertaken separately by academics and practitioner researchers but that joint working between academic and commercial marketing researchers represents another dimension to marketing research which could be facilitated by the creation of joint initiatives, including industry-inspired academic-practitioner research projects and the development of government-funded academic-practitioner research projects, building on both groups' unique sets of skills. 


\section{Originality/value of paper}

Reports on the outcome of an empirical study that has implications for the conduct of marketing research in universities and market research agencies.

\section{Keywords}

Marketing research; research relevance; academic/practitioner divide

\section{Classification}

Commentary 


\section{Examining The Academic/Commercial Divide in Marketing Research}

\section{Introduction}

In this study we compare and contrast the attitudes of academic and professional marketing researchers towards their own and each other's work and towards the field of marketing research in general. The aim is to investigate the attitudes of active researchers, to provide a new dimension to a debate that has previously been conducted largely on the basis of argumentation or anecdote (Piercy, 2006; Campbell, 2006; Zinkhan, 2006; Keegan, 2007). In addition, we aim to contribute towards the continuing debate in the marketing academy on issues such as the "academic/practitioner divide" and the "relevance gap in academic research" (Baker 2001; Starkey \& Madan 2001, McDonald, 2003); not least because the relationship between academic research and marketing practice is a subject of enduring interest (Catterall, 1998; Baker, 2001; Wensley, 2002; Brennan, 2004).

In this article we present a summary of the 'academic/practitioner divide' debate in marketing, then report the results of our empirical study, and finally consider the desirability and feasibility of greater collaboration between academic and commercial market researchers.

\section{The Case for Relevance}

Piercy (2000; 2002) and Tapp (2004) argue that academic marketing researchers should make their work relevant to marketing practitioners. To do this, they must find out what kinds of research managers value and then make their results accessible to managers by publishing intelligible articles in media that managers read - for example, Piercy (2002) asserts that Jagdish Sheth sees the Wall Street Journal and Fortune magazine as highly desirable publishing outlets. 
However, to achieve success in their careers marketing academics must publish in 'highly rated' journals, and academic journals in marketing are seldom read by marketing practitioners (McKenzie et al 2002). This creates a perverse incentive structure since to achieve academic 'success' academics must publish in outlets that are largely unknown by marketing practitioners. Consequently, "the position has been reached in many schools where emphasising relevance in your research and publishing involves significant career-related risks" (Piercy, 2002:359). Piercy (1999) has argued that this situation is compounded by the fact that many academic marketing researchers are ambivalent about the status of marketing as an academic discipline, and indeed would prefer to be working in a "proper" discipline such as economics or psychology instead. The views of Piercy (2002) and of Tapp (2004) constitute a clear and coherent view of the role of academic marketing research as essentially a service industry aligned with the commercial world of marketing. According to this line of reasoning, the following represents a position that is espoused by some marketing scholars:

Argument 1: academic research in marketing should be made more relevant to commercial practice, because the primary purpose of the marketing academy is to support the marketing industry.

\section{A Contrary Case}

Since marketing is essentially a practical discipline, it may seem self-evident that academic research should be relevant to practitioners. However, even if it is largely a practical discipline, is marketing exclusively so, or is there room for a body of "pure marketing theory"? Additionally, there is the question of interest groups. Is there some reason why marketing practitioners should have a privileged stakeholder position when it comes to the application of academic research results? 
There seems to be no prima facie reason why marketing practitioners should be the main beneficiaries of academic marketing research (Grey, 2001). Academic research, other than contract research, is largely funded by the state out of general taxation. It is not obvious why the benefits of academic marketing research should accrue solely or largely to one interest group, particularly when that interest group is in a powerful position in society and has plentiful resources. This brings us to a position that is contrary to argument 1 , but which is espoused by other marketing scholars:

Argument 2: academic marketing research (funded from general taxation or via charities) should address issues primarily of concern to less privileged groups within society, suggesting that marketing academics should concern themselves more with topics that have a wider value in society rather than aiming to assist marketing practitioners.

\section{Research Methodology and Sample Design}

Given these contradictory views of what role marketing research should play, we conducted a programme of empirical research designed to address the following objectives:

1. a) To assess how professional market researchers perceive their own work and the work of academic marketing researchers.

b) To assess how academic marketing researchers perceive their own work and the work of professional market researchers.

2. To identify and explore ways in which these two groups can more effectively communicate their market research activities to one another, collaborate on projects 
together (assuming that they can) and more effectively work on areas of common interest.

There were two empirical phases to the study. In the first qualitative phase, we conducted two discussion groups, one of senior marketing academics and one of senior professional market researchers, in London. The second, quantitative phase of the work comprised a web-based survey conducted among the academic and practitioner researcher communities. The academic sample (1,484 people) was compiled using a list of members of the largest UK membership organisation for marketing academics. The market research practitioner sample $(2,167$ people) was compiled from a membership list of UK market research professionals.

128 usable replies were received from academics (response rate 9\%), and 510 usable responses from practitioners (response rate 24\%). The academic response rate is disappointingly low, although similar to response rates of academic surveys previously conducted amongst academic marketers (Baker and Erdogan, 2000; Polonsky and Mankelow, 2000), indicating that this population is probably, and ironically, not particularly responsive to surveys.

\section{Findings}

\section{The Practitioner Perspective}

From the discussion groups, we found that the two communities have reasonably congruent views of each other and themselves. They perceive each other to be doing different things in different environments, with limited room to work together on joint research projects. 
Academics on the other hand would welcome access to market research agency data, providing that it is of good quality.

Market research practitioners do not find research findings disseminated through academic journals useful. Figure 1 illustrates the "net useful" ratings our sample of research practitioners give to four different sources of marketing research information (the "net useful" figure is the difference between the percentage of respondents citing each source as [very or fairly] useful and not [very or at all] useful). On this measure, web sites (+74) and professional magazines $(+56)$ are considered the most useful. Not only do academic journals (-19) come behind newspapers (-2), but the majority of research practitioners (55\%) expressly claim that academic journals are not useful sources of professional information.

\section{Figure 1: Usefulness of Sources}

\section{How useful do you find the following as sources of professional information?} (Practitioners)

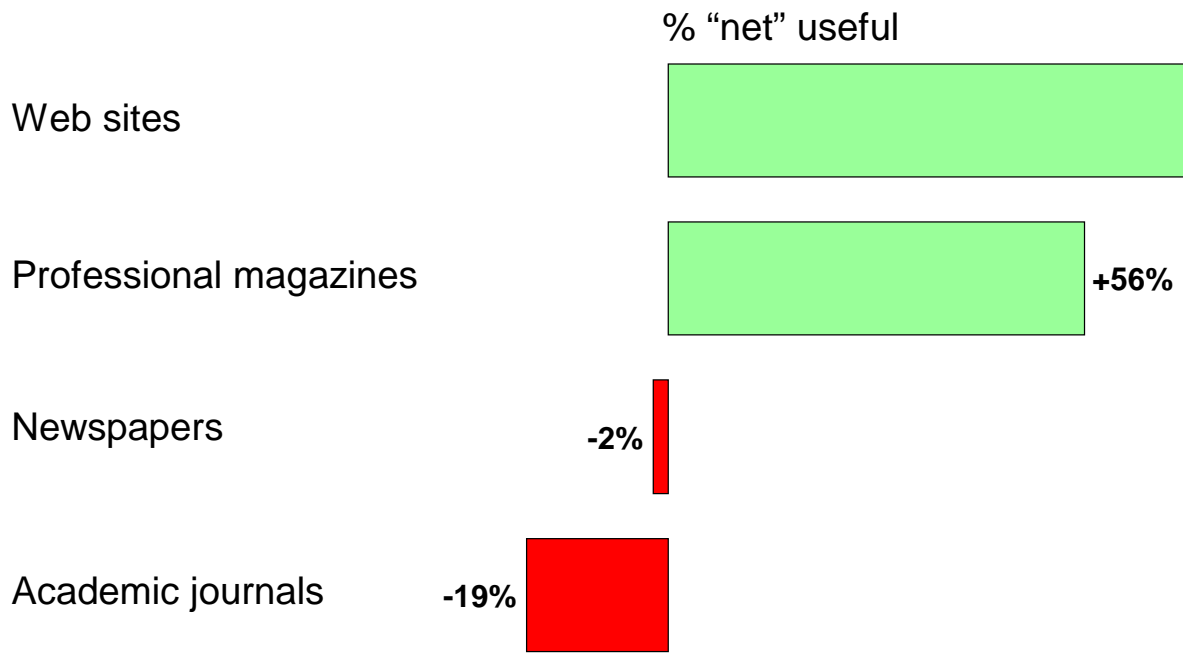

Base: 510 marketing research practitioners. Fieldwork: 8 September - 29 September 2006

The consensus among our sample of practitioners $(81 \%)$ is that marketing managers do not read academic marketing journals. We asked our sample of practitioners whether they knew about certain academic journals. The results are illustrated in Figure 2, which shows the 
proportion that feel they know either a fair amount or a great deal about each journal. Only the International Journal of Market Research (formerly the Journal of the Market Research Society) is well known among research practitioners. For two of the publications, more than half of practitioners said they had never heard of them: the European Journal of Marketing (54\%) and the International Journal of Public Opinion Research (63\%).

Figure 2: Knowledge of Journals

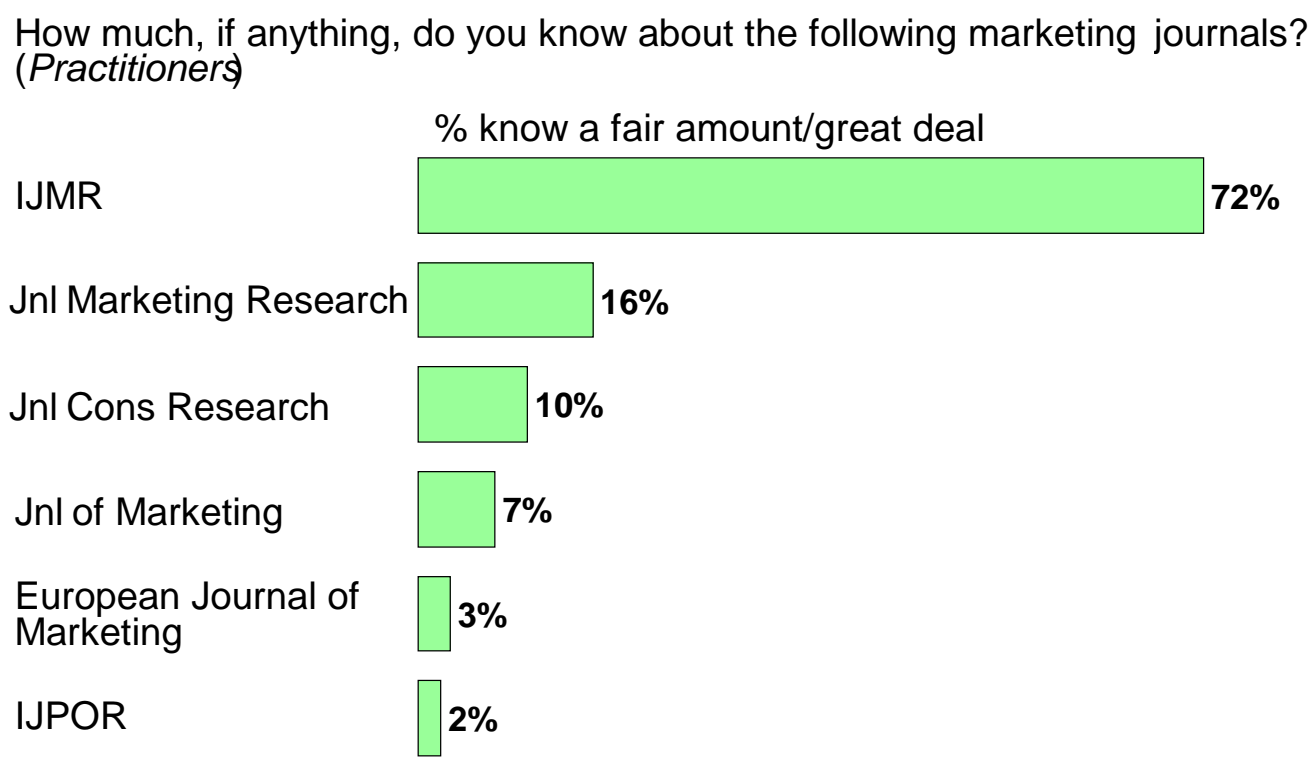

Base: 510 marketing research practitioners. Fieldwork: 8 September - 29 September 2006

\section{The Academic Perspective}

Most of the academic respondents (74.4\%) had been involved in marketing research consultancy at some time during their careers. In order to ascertain how involved in market research projects our sample were at present, we asked how 'active' they perceived themselves to be in marketing research consultancy at present. Only $3 \%$ regarded themselves as 'highly active', 20\% 'active', 46\% 'not very active', and 31\% 'inactive'. The majority of our academic marketing respondents saw themselves as part-time researchers; the modal category for the amount of hours per week spent on marketing research was 1-10 hours 
(44.4\%), and only $17.1 \%$ of academic respondents reported that they spend more than 20 hours per week working on research.

Marketing academics are even more likely than market researchers (88\% and $71 \%$, respectively) to believe there should be more collaboration between academic marketing researchers in universities and market research agencies. But there is a disagreement between the two groups on whether there should be competition between them. On balance, the practitioner sample believe that direct competition should be avoided (43\% say it should be avoided, $37 \%$ say it should not), while the academic sample are more likely to favour competition (32\% avoided vs. $51 \%$ not avoided). A very high proportion of our sample of marketing academics (88\%) also say that they think academic marketing research should be of practical value to marketing managers - although, as shown later, academics are split on whether academic research actually is typically of value to these managers.

Marketing academics believe that marketing managers would be interested in their own current research. One in three $(32 \%)$ of our sample of marketing academics claim managers would be very interested and just over half (55\%) think they would be fairly interested. Only $13 \%$ believe managers would not be interested. Furthermore, there is a sense that the relevance of academic marketing research grows over time. When asked "Once completed how relevant, if at all, will your research be to marketing managers in the short term (next 12 months), medium term (next 2 to 5 years) and long term (more than 5 years)?", $30 \%$ of our academic sample felt it would be relevant in the short term, $35 \%$ in the medium term, and $43 \%$ in the long term, indicating a tendency towards the belief that academic research is of greater practical value in the long term. But academics recognise that this is not always perceived to be the case by marketing managers themselves, with three in five $(60 \%)$ 
academics believing that managers are not enthusiastic about adopting ideas from academic marketing research. Just one in twenty (5\%) believe managers are generally very enthusiastic, and a third (35\%) believe they are fairly enthusiastic.

\section{Comparative Analysis}

To measure the salience of a number of characteristics of research in marketing, we asked both academic and practitioner researchers to rate how important it is for marketing research to meet certain criteria. The results are presented in Figure 3 in the form of "net importance" (the "net importance" figure is derived from calculating the difference between the percentage of respondents saying each factor is [very or fairly] important and not [very or at all] important). There are several areas of agreement between academic and practitioners; both groups believe that market research should be of a high standard, professional, comprehensible and published quickly. Only on two factors do we see a major difference in views; academics are much less likely to believe that market research should be businessfocused (39 point difference) and useful to managers (30 point difference). 


\section{Figure 3: Marketing Research Should be ...}

How important is it that marketing research be...

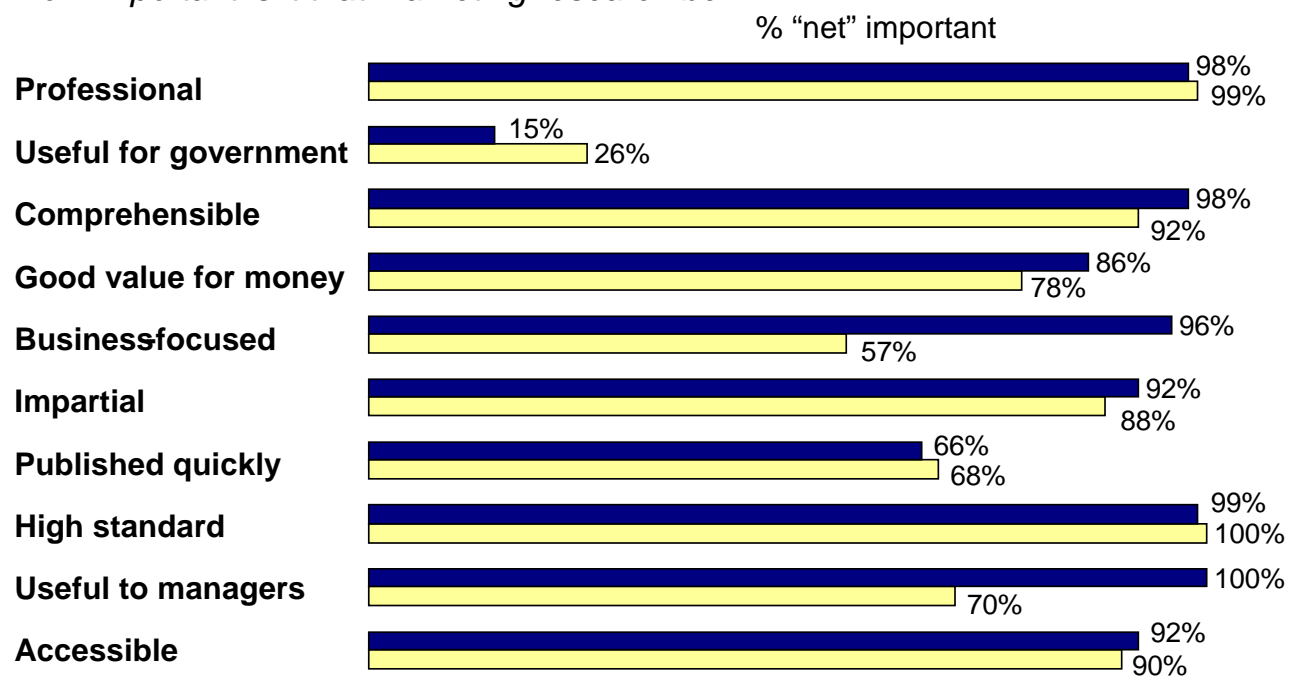

Base: 510 MR practitioners and 128 MR academics. Fieldwork 29 June $-29^{\text {th }}$ September 2006

We then investigated how well 'academic' and 'practitioner' market research performed against the criteria for "importance". For this we used a 7-point bipolar semantic differential scale, asking respondents for their views of "academic marketing research" ('research undertaken by people working in universities or other higher educational institutions as part of their normal responsibilities') and "practitioner marketing research" ('research undertaken by people working for market research agencies on behalf of their clients'). To make straightforward comparisons between the two groups and their ratings on all attributes, we used the correspondence analysis technique to produce a 'perceptual map' (Hair et al, 1995; Everitt and Dunn, 2001). A particular strength of the technique is that it enables items of differing salience to be compared on an equal basis; hence practitioners' and academics' perceptions of each other can be compared in a diagram of "image space" based on differences between these perceptions. The ellipses are not part of the correspondence analysis, but are added for ease of visual reference. 
Figure 4: Academics’ Perceptions of Marketing Research

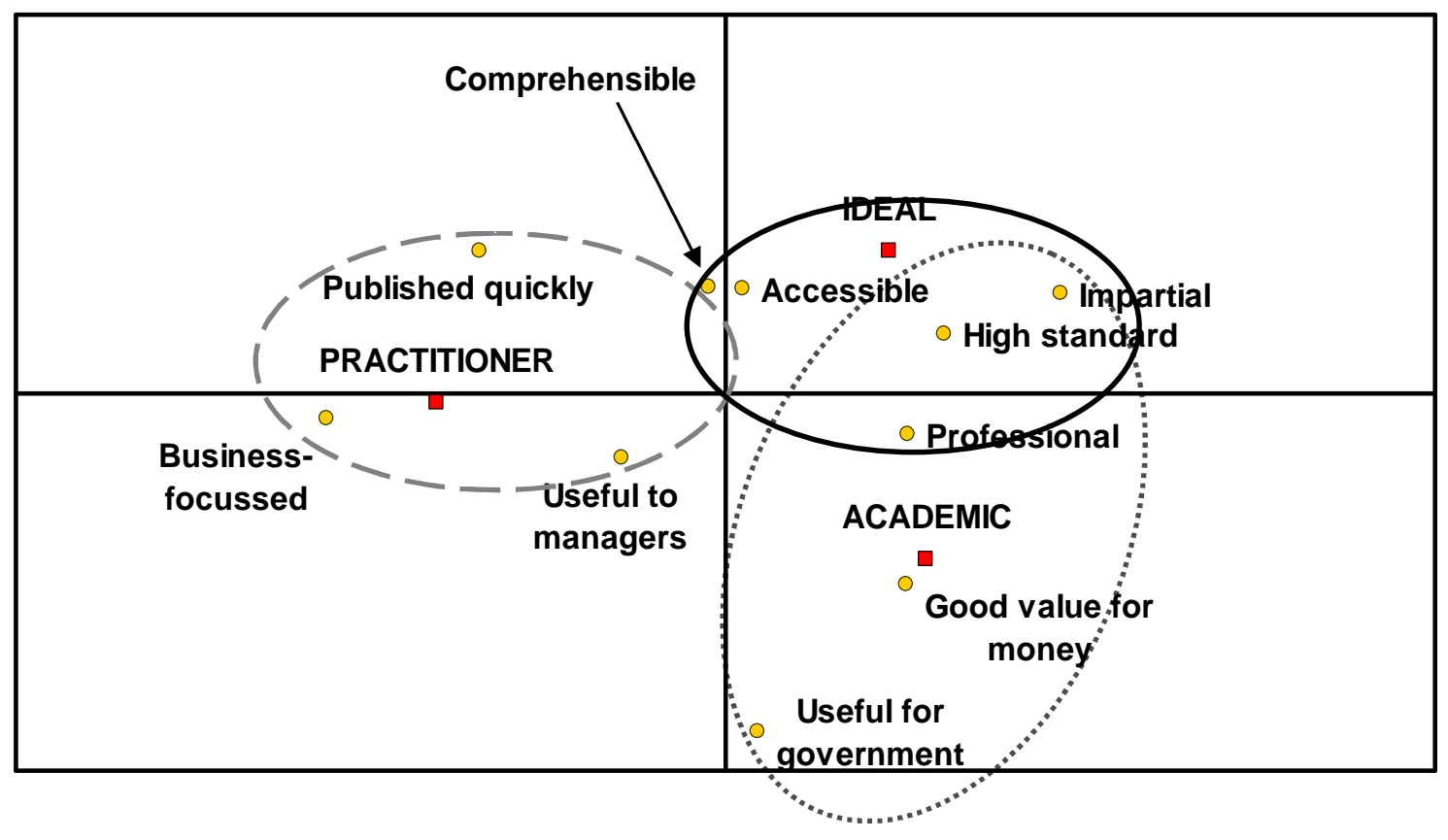

Figure 4 shows how academics perceived their own research and practitioner research in comparison with the criteria they value as important (the "ideal") so the findings are both descriptive and normative (i.e. how research ought to be). Note that what is portrayed is their relative impressions of academic and practitioner research - which descriptions apply most distinctively to each. Figure 4 illustrates that marketing academics perceive practitioner research to be published quickly, business-focused and useful to managers; these are attributes that academics value less highly than practitioners. Academics perceived their own research to be impartial, of a high standard, professional, good value for money and useful for government. The ideal form of research for academics would be accessible, of a high standard, professional, comprehensible and impartial.

Figure 5 illustrates the perceptual map for the sample of market research practitioners. Practitioners perceived their own research to be business-focused, value-for-money, published 
quickly and useful for government. They perceived academic research to be useful for government, professional, of a high standard, and impartial.

Figure 5: Practitioners' Perceptions of Marketing Research

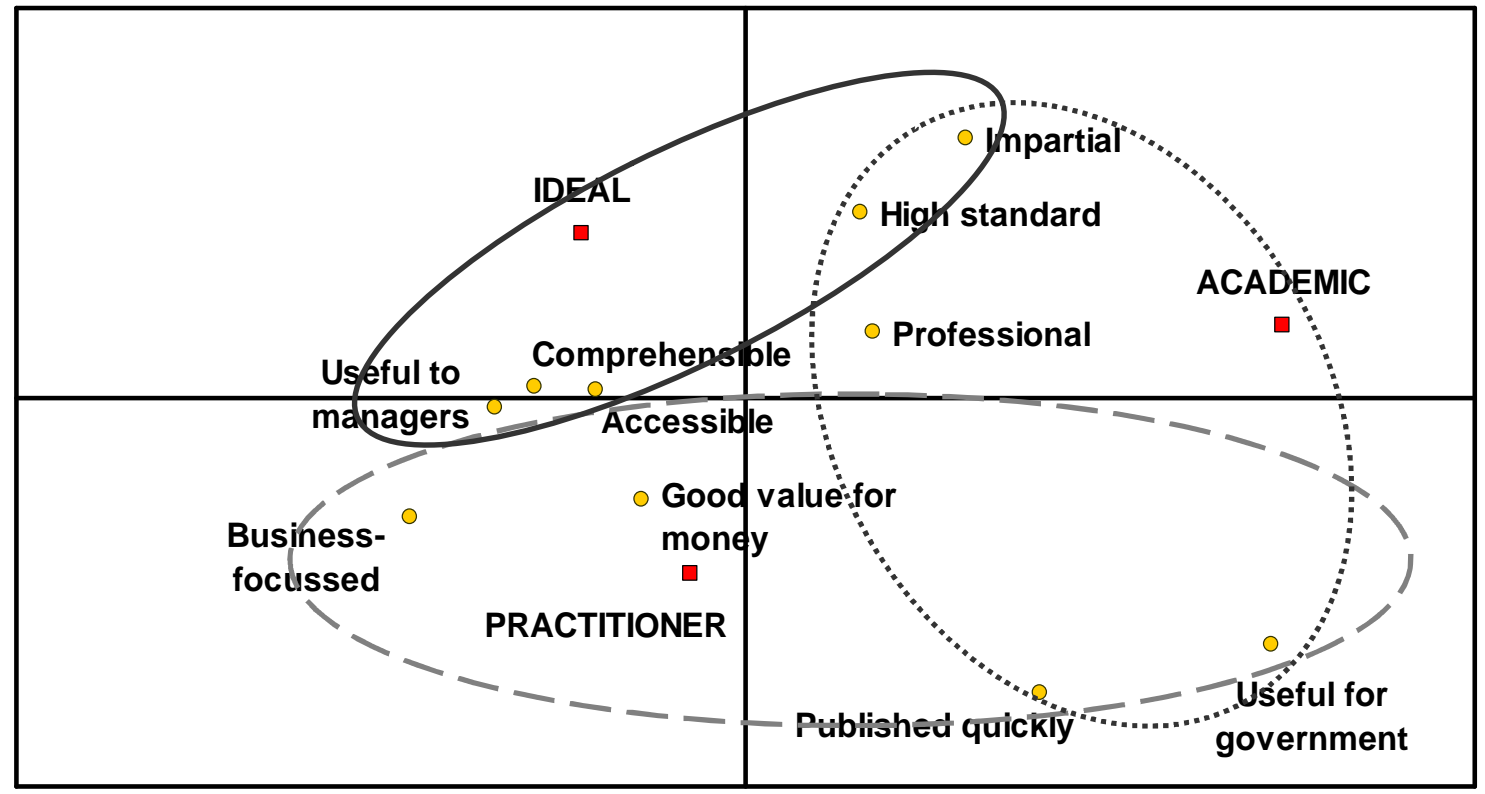

\section{Discussion}

Marketing academics and market research practitioners have similar views of the salient characteristics of good marketing research. However, marketing academics have little to do with marketing practice, conduct research on a part-time basis, and revere work that appears in peer-reviewed academic journals. By contrast, market researcher practitioners seem to worry less about methodological minutiae; the key aim of practitioners is to satisfy the research needs of the paying client, making the accumulated research knowledge in academic journals seem irrelevant because it is produced for a different purpose. This brings the discussion to our need to identify and explore ways in which these two groups can more effectively communicate their market research activities to one another, collaborate on projects together (assuming that they can) and more effectively work on areas of common 
interest.

We have uncovered some evidence to support the idea that marketing academics have the skills and inclinations pertaining to analysis of longer-term trends and underlying causal mechanisms in markets. Equally, as one would expect, the principal concern of market research practitioners is to provide pragmatic support for short-term decision-making. Clearly this is merely a useful generalisation and exceptions can be found: $3 \%$ of the academic respondents reported themselves to be 'highly active' in commercial market research and consultancy; $17 \%$ of the practitioners said they had written an article for an academic journal. But it is a fairly good generalisation: $54 \%$ of the practitioner sample had never heard of the European Journal of Marketing; the great majority of marketing academics have either never done any commercial market research, or are currently inactive in this area.

Concerning the possibility of greater collaboration between academic and commercial marketing researchers, we would say that our research provides grounds for both optimism and pessimism. Optimistically, we can say that research academics and research practitioners in marketing hold similar views of what constitutes good research in marketing, and there is evidence of a degree of mutual respect. For example, academics approve of the speed that practitioners publish their findings, and think that they are presented in a readily digestible form; practitioners think that academic research is impartial and conducted professionally. Pessimistically, there is evidence that the two groups run along parallel tracks, both investigating marketing phenomena, but seldom if ever engaging with each other, meeting in their own groups at their own conferences, and communicating within their groups using their own media. Under these circumstances, how might greater engagement between market research academics and practitioners be achieved? 
We suggest that greater collaboration can be pursued under three headings: mutual comprehension, joint communication, and joint research. Under the heading of mutual comprehension are initiatives such as secondments (of academic staff to market research agencies, and of research practitioners to academic departments), internships (of $\mathrm{PhD}$ students at market research agencies), and greater cross-fertilisation between academic and practitioner conferences. These are inexpensive activities that essentially require the will to do them, plus a little time and money. Secondments and internships need be for no longer than a few weeks for mutual comprehension to improve and for personal networks to be formed. Joint communication involves purposeful activity to increase the frequency with which academic results are reported in the preferred media of practitioners, and the frequency with which the practitioner perspective is represented in academic journals. The European Journal of Marketing (and similar journals), for example, could invite brief commentaries from prominent practitioners on current marketing affairs and the research priorities that these imply. Again, such initiatives are neither particularly time-consuming nor costly. However, the third possibility - joint research - is more problematic. In principle, this may be no more than a call for a European version of the American Marketing Science Institute, which describes itself as "a learning organization dedicated to bridging the gap between marketing science theory and business practice" (MSI 2008). In practice, this would be much harder to accomplish, involving far greater investments of time and money. For the moment, we would suggest that this is a long-term aspiration that would be facilitated if the medium-term, and quite feasible, aims of mutual comprehension and joint communication were put in place.

\section{Conclusion}


There are those, among marketing academics and market research practitioners, who consider that greater collaboration between the two would bring mutual benefit. Equally, there are those, among both groups, who want nothing to do with the other - some practitioners who are quite happy to leave marketing academics to what they perceive as their own irrelevance, and some academics who believe that any dalliance with the commercial world imperils the objectivity of the research process $(28 \%$ of our academic respondents think that there is a 'substantial risk' that academics endanger 'rigour' when they seek to be 'relevant'). Both these positions imperil the advancement of marketing research more generally because they adopt an 'either-or' position and can be characterised, in terms of logic, as adopting a fallacy of the extreme - that is to say one or other of the two extreme positions outlined earlier in this commentary. However, it is equally reasonable to argue for a middle way between these two extremes. In other words, the two groups can work both together and separately, thus covering all possible stakeholder needs across clients, government and society (see Table 1).

Table 1: Marketing Research Orientations

\begin{tabular}{|c|c|c|c|}
\hline & \multicolumn{3}{|c|}{ PARTNERSHIP ORIENTATION } \\
\hline \multirow{3}{*}{$\begin{array}{c}\text { RESEARCH } \\
\text { FOCUS }\end{array}$} & & Single & Joint \\
\hline & Practitioner & $\begin{array}{l}\text { Research undertaken } \\
\text { on behalf of one or } \\
\text { more commercial } \\
\text { clients purely for the } \\
\text { purposes of that client }\end{array}$ & \multirow{2}{*}{$\begin{array}{l}\text { Research undertaken on behalf of } \\
\text { one or more commercial clients, } \\
\text { but which also has a wider social } \\
\text { purpose, with a view to } \\
\text { understanding the longer-term } \\
\text { implications of marketing practice } \\
\text { and phenomena and their impact on } \\
\text { society. }\end{array}$} \\
\hline & Academic & $\begin{array}{l}\text { Research undertaken } \\
\text { on behalf of } \\
\text { government, charity } \\
\text { or research council } \\
\text { for the purposes of } \\
\text { improving society. } \\
\text { Pure research } \\
\text { undertaken for the } \\
\text { purpose of advancing } \\
\text { marketing theory. }\end{array}$ & \\
\hline
\end{tabular}


This research indicates tentatively that there is sufficient common ground between marketing research academics and marketing research practitioners to make improved cooperation a feasible goal. The sheer efficiency and data collection capabilities of market research practitioners, combined with their important skills of client-handling and understanding managerial problems, complement the longer-term multi-stakeholder perspective of academic researchers and may facilitate long-term blue-skies research projects in marketing. In the short term it would make sense to aim for greater mutual comprehension and joint communication through modest initiatives such as secondments and 'practitioner perspectives' in academic journals. In due course, such initiatives may form the basis for longer-term research collaboration.

\section{References}

Baker, M. J. (2001). Commentary: Bridging the divide. European Journal of Marketing, 35(1/2), 24-26.

Brennan, R. (2004). Should we worry about an academic-practitioner divide in marketing? Marketing Intelligence and Planning, 22(5).

Campbell, R. (2006), Response to 'The trouble with marketing research is marketing researchers' by Nigel F. Piercy", International Journal of Market Research, Vol.48, No.5.

Catterall, M. (1998). Academics, practitioners and qualitative market research. Qualitative Market Research: An International Journal, 1(2), 69-76.

Everitt, B.S. and Dunn, G. (2001), Applied Multivariate Data Analysis, $2^{\text {nd }}$ edition, London: Arnold, pp.74-91.

Grey, C. (2001). Re-imagining Relevance: A Response to Starkey and Madan. British Journal of Management, 12(Special Issue), S27-S32. 
Hair, J.F., Jr.; Anderson, R.E., Tatham, R.L. and Black, W.C. (1995), Multivariate Data Analysis with Readings, 4th Edition, Englewood Cliffs, NJ: Prentice-Hall, pp.516-527.

Keegan, S. (2007), "Viewpoint: The commercial academic divide: never the twain shall meet?", International Journal of Market Research, Vol.49, No.1, 9-11

McKenzie, C. J., Wright, S., Ball, D. F., \& Baron, P. J. (2002). The publications of marketing faculty - who are we really talking to? European Journal of Marketing, 36(11/12), 1196-1208. McDonald, M. (2003). Marketing: priority case for a reality check. The Marketing Review, Vol.3.

MSI (2008). “About the Marketing Science Institute". Internet source, available at http://www.msi.org/about. Accessed 28th February 2008.

Piercy, N. (1999). In search of excellence among business school professors: cowboys, chameleons, question-marks and quislings. European Journal of Marketing, 33(7/8), 689-706. Piercy, N. (2000). Why it is fundamentally stupid for a business school to try to improve its research assessment exercise score. European Journal of Marketing, 34(1/2), 27-35.

Piercy, N. (2002). Research in marketing: teasing with trivia or risking relevance? European Journal of Marketing, 36(3), 350-363.

Piercy, N. (2006), The trouble with marketing research is marketing researchers. International Journal of Market Research, Vol.48, No.3.

Tapp, A. (2004). A call to arms for applied marketing academics. Marketing Intelligence and Planning, 22(5), 579-590.

Wensley, R. (2002). A bridge over troubled water? European Journal of Marketing, 36(3), 391-400.

Zinkhan, G.M. (2006), "Research traditions and patterns in marketing scholarship“, Journal of the Academy of Marketing Science, Vol.34, No.3, pp. 281-283. 